\title{
The effects of analytic group therapy compared with pharmacotherapy in patients with anxiety disorders
}

\author{
Saman Sedighi ${ }^{1}$, Soodeh Rahmani ${ }^{1}$, Mahdieh Moinolghorabaei ${ }^{2, *}$
}

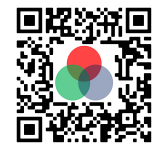

Use your smartphone to scan this QR code and download this article

${ }^{1}$ Psychotherapy research center, Roozbeh hospital, Tehran University of medical sciences, Tehran, Iran

${ }^{2}$ Psychiatry and Psychoanalytic Psychotherapy, Department of Psychotherapy, Roozbeh hospital, Tehran University of medical sciences, Tehran, Iran

\section{Correspondence}

Mahdieh Moinolghorabaei, Psychiatry and Psychoanalytic Psychotherapy, Department of Psychotherapy, Roozbeh hospital, Tehran University of medical sciences, Tehran, Iran

Email:m.moin2020@protonmail.com

History

- Received: Oct 17, 2020

- Accepted: Dec 10, 2020

- Published: Dec 29, 2020

DOI : 10.15419/bmrat.v7i12.653

\section{Check for updates}

\section{Copyright}

(- Biomedpress. This is an openaccess article distributed under the terms of the Creative Commons Attribution 4.0 International license.

\begin{abstract}
Background: Psychotherapy and pharmacotherapy are both effective in the treatment of anxiety disorders. However, drugs in pharmacotherapy are often compared with placebo controls, and psychotherapy is mostly compared to patients in the waiting list as the controls. We aimed to compare the effects of analytic group therapy with pharmacotherapy in patients with anxiety disorders. Methods: In this clinical trial study in Tehran, 65 patients (10 males, 55 females) presenting with a primary diagnosis of panic disorder, generalized anxiety disorder, and/or mixed anxiety-depressive disorder (based on a structured clinical interview by a psychiatrist) were enlisted during the period from 2016 to 2018. The patients were randomly divided into two groups: drug therapy (group D, 33 patients), or drug therapy + analytic group therapy (group G, 32 patients). Anxiety was assessed in both groups before and immediately after treatment by the Persian version of the Hamilton Anxiety scale (HAM-A). Collected data were analyzed by SPSS statistical software version 21. Results: Both groups showed a statistically significant decline in HAM-A scores after the treatment. However, group $\mathrm{G}$ had a greater significant change in anxiety score compared to group D. The mean decline of HAM-A was $25.69 \pm 4.82$ for group $G$ and $23.21 \pm 4.64$ for group D. The HAM-A score was significantly reduced in group $\mathrm{G}$ compared to group $\mathrm{D}(\mathrm{p}=0.039)$. Conclusion: This study showed that psychodynamic psychotherapy could improve the pharmacotherapy effects and is superior to pharmacotherapy alone.

Key words: Anxiety disorder, effectiveness, group therapy, pharmacotherapy, psychodynamic psychotherapy
\end{abstract}

\section{INTRODUCTION}

Anxiety disorders are known as the most common psychiatric disorders in the general population that often have a substantial impact on a person's daily life ${ }^{1-3}$, and are associated with different comorbidities $^{4-6}$. They are categorized into various disorders that have similar features, such as fear and excessive anxiety, and result in behavioral disorders ${ }^{4}$. Phobias are the most prevalent anxiety disorder, with a 12 -month prevalence of $10.3 \%{ }^{7}$. The next most prevalent one is panic disorder (PD)- with or without agoraphobia- which has a prevalence of $6 \%$. Social anxiety disorder $(2.7 \%)$ and generalized anxiety disorder $(2.2 \%)$ are the next most frequent ${ }^{8,9}$. Diagnosis of anxiety disorders is $1.5-2$ times more common in women compared to men ${ }^{10}$.

In clinics, most patients with anxiety disorders who seek help are suffering from generalized anxiety disorder (GAD), pathological demand avoidance (PDA), and seasonal affective disorder $(\mathrm{SAD})^{10}$. Their treatment can be performed most of the time in an outpatient setting ${ }^{11}$. Many studies have shown the efficacy of medications for GAD, PDA and SAD, but there are very few treatment studies for specific phobias ${ }^{12}$. Supportive talks and attention to the emotional issues of anxiety patients are important in the treatment of these patients. Psychoeducation and provision of information on the physiology of symptoms of anxiety and available treatment options can be helpful ${ }^{11}$.

Cognitive behavioral therapy (CBT) as a practical and structured form of psychotherapy has been shown to be effective in the treatment of anxiety disorders ${ }^{13-16}$. Several methods and techniques have been used to understand and manage the cognitive, behavioral, and physiological parts of anxiety ${ }^{17}$. In comparison, with CBT, the evidence for psychodynamic (analytic) psychotherapy is weaker ${ }^{18}$. Meanwhile, studies assessing psychodynamic psychotherapy for anxiety disorders are fewer in number and have lower quality. It has been shown that some patients do not respond to CBT, continue to have symptoms, terminate early, and/or relapse after treatment ${ }^{19,20}$. Moreover, a few studies have shown a worsening of anxiety by CBT in some patients ${ }^{21}$. Thereby, investigating different treatment options is important. Since psychodynamic psychotherapy is widely used as an effective 
treatment for anxiety, it is necessary to prove its effectiveness.

Psychotherapy and pharmacotherapy are both more effective in patients with anxiety (compared to control groups) in the treatment of their anxiety disorders. However, pharmacotherapy-treated patients are often compared with placebo-administered control subjects, and psychotherapy patients are mostly compared to patients in the in the waiting room in Roozbeh psychiatric hospital, Tehran university of medical sciences (the controls with no psychotherapy or treatment) ${ }^{14,22,23}$. Therefore, there is a lack of knowledge in controlled studies comparing psychodynamic therapy and pharmacotherapy in these patients. We aimed to compare the effects of analytic group therapy with pharmacotherapy in patients with anxiety disorders.

\section{METHODS}

This controlled clinical trial study was performed on patients with an initial diagnosis of anxiety disorders who had been referred to the Roozbeh General Psychiatric Clinic, a private clinic in Tehran, Iran, between the years of 2016-2018. The study protocol was approved by the Medical Ethics Committee of Tehran University of Medical Sciences, and the investigation was granted an ethical code of IR.TUMS.REC.1394.1004, which was confirmed in January 2016. Patients were enlisted who presented with a primary diagnosis of PD, GAD, and mixed anxiety-depressive disorder, based on a structured clinical interview for depression care management (DCM) by a licensed psychiatrist. Patients were divided into 2 random groups using block randomization method and Random Allocation software version 2 (Statistic, Germany). After obtaining their informed consent, the 65 patients ( 10 males, 55 females) were divided into the two groups: drug therapy (group D, 33 patients), or drug therapy + analytic group therapy (group G, 32 patients).

Exclusion criteria for both groups included dementia, mental retardation (or any organic brain syndrome), treatment with any other therapeutic approaches (pharmacotherapy or psychotherapy) by another psychiatrist, indication of hospitalization, inability to tolerate group space, severe personality disorder (borderline or schizoid), and the absence of motivation to improve (all assessed and defined by a psychiatrist).

Group D patients were treated with Sertraline (150 mg daily) and Alprazolam (0.5-1 mg daily) for 6 months. Group $G$ patients, in addition to these drugs, participated in a $1.5 \mathrm{~h}$ session once weekly for a period of 6 months. The group therapies were held at the Roozbeh General Psychiatric Clinic by a trained group analyst. Patients participated in open groups and even continued the group therapy after 6 months. The aim of the group therapy sessions was allow each individual to reflect on his/her own experiences, while being emotionally linked, so that their personalities could emerge. Some patients' experiences were connected to others' experiences, generating fantasies and theories for that person and the others. The reflective space was constructed by the existing links (theories and fantasies) or by the damaged effects following violent attacks upon the patients. The connection between the minds can undergo a similar set of changes. Their interactions might be different, such that one's mind can accept, reflect upon (link up with), and/or take in the anxiety and emotions of others. In general, a therapeutic group tries to construct a culture of emotional connection between individuals so that it becomes a container in which the members' experiences can be arranged, reflected upon, and more or less guarded from attack ${ }^{24}$.

Anxiety was assessed in both groups before and immediately after treatment by the Persian version of the Hamilton Anxiety scale (HAM-A) ${ }^{25}$. The questionnaire consisted of 14 items, each containing several terms as explanations and definitions, and was completed by the therapist. Each item was rated on a 5-point Likert-type scale ranging from 0 to 4 . Total HAM-A score was between 0 to 56 . Higher scores indicated greater severe anxiety than lower scores.

The collected data were analyzed by SPSS statistical software version 21 (SPSS Inc, Chicago, USA). Qualitative variables were described by frequency and percentage, and quantitative variables were described as mean and standard deviation. The normality of data was tested by Shapiro-Wilk test. Chi-squared test and Fisher's exact test were used to assess the relationship between qualitative variables. The relationships between quantitative variables were analyzed by $\mathrm{T}$ test and Mann-Whitney $\mathrm{U}$ test for non-normal distributed variables, when necessary. In all analyses, $\mathrm{P}$ value $<0.05$ was considered to be statistically significant.

\section{RESULTS}

In this study, age, sex, and pre-treatment HAM-A score variables in the two groups were examined and compared. The results of this study are reported in Table 1. The mean and standard deviation of the age of patients in group $\mathrm{G}$ was $35.53 \pm 7.65$ and in group $D$ was $33.46 \pm 8.14$; there was no significant difference in terms of age observed between the two groups $(\mathrm{p}=$ $0.295)$. In group $G$, out of 32 participants, $26(82 \%)$ 


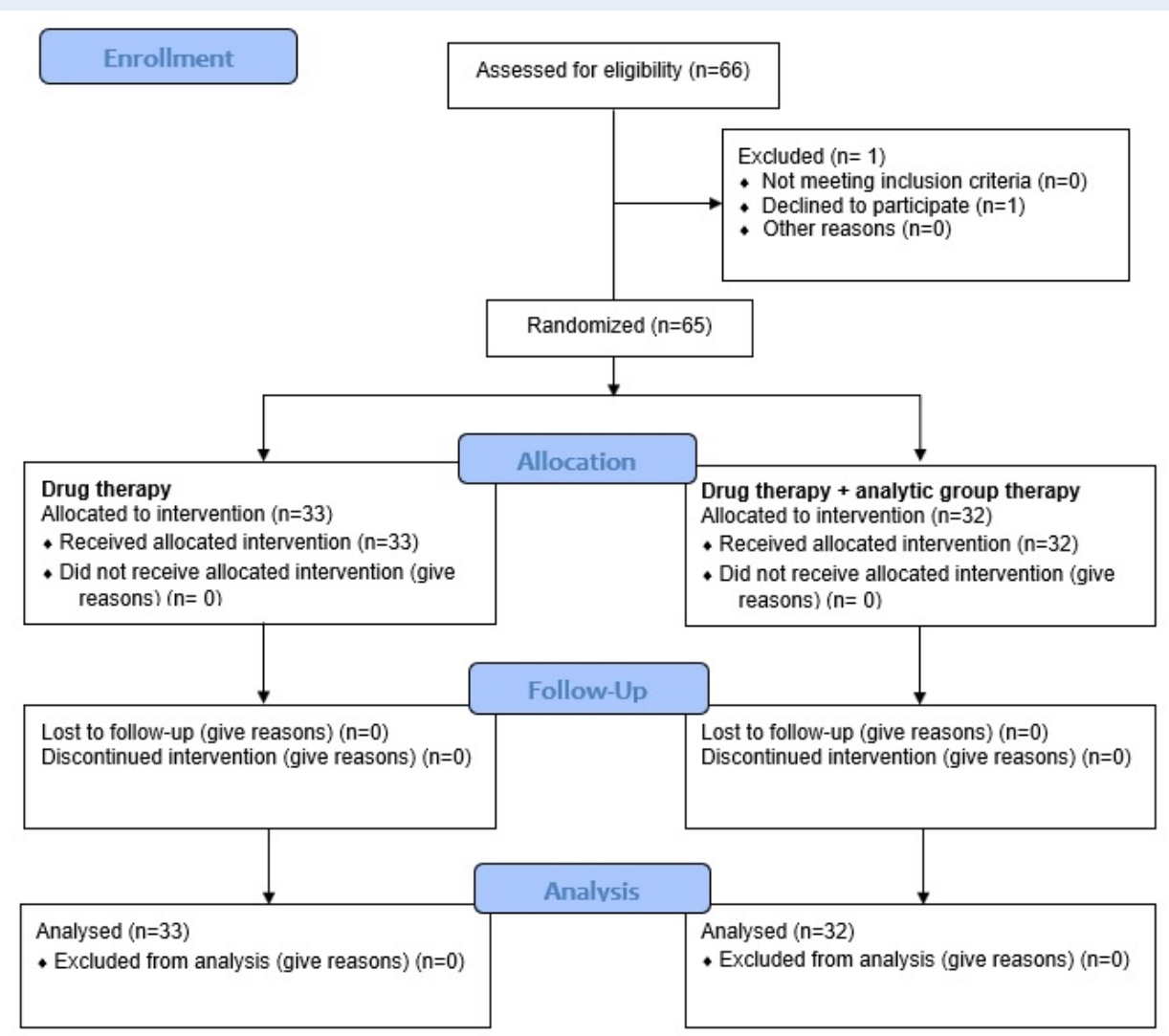

Figure 1: CONSORT flowchart for participated in this study.

Table 1: Comparison of baseline characteristics in two groups

\begin{tabular}{lccc}
\hline Characteristic & Group G (N = 32) & Group D (N = 33) & P-value \\
$\begin{array}{l}\text { Age (years) } \\
\text { mean (SD) }\end{array}$ & $35.53(7.65)$ & $33.46(8.14)$ & 0.295 \\
$\begin{array}{l}\text { Female gender } \\
\text { N } \%)\end{array}$ & $26(82)$ & $29(88)$ & 0.501 \\
$\begin{array}{l}\text { Pre-treatment HAM-A score } \\
\text { mean (SD) }\end{array}$ & $31.53(3.06)$ & $31.12(2.96)$ & 0.584 \\
\hline
\end{tabular}

were female and $6(18 \%)$ were male. In group D, out of 33 participants, 29 (88\%) were female and 4 (12\%) were male. Thus, in terms of gender, no significant difference was observed between the two groups $(p=0.501)$. Other details are reported in Table 1 . The two groups were not statistically different in their pretreatment HAM-A scores $(\mathrm{p}=0.584)$.

Moreover, the HAM-A scores after treatment were compared for the two intervention groups. The results of this evaluation are reported in Table 2 and Figure 2. The mean difference of the HAM-A scores of the patients before and after treatment for group $G$ was 52.69 and for group D was 23.21. As shown in Table 2, both groups showed a statistically significant decline in HAM-A scores after the treatment. However, group $\mathrm{G}$ had a greater significant change in anxiety score compared to group $\mathrm{D}$. The mean and standard deviation decline of the HAM-A score was 25.69 \pm 4.82 for group $\mathrm{G}$ and $23.21 \pm 4.64$ for group $\mathrm{D}$. The HAM-A score showed a statistically greater decline in group $\mathrm{G}$ compared to group D ( $\mathrm{p}=0.039)$. Male patients were removed from the table due to their small number $(\mathrm{n}=10)$. 
Table 2: Changes in HAM-A scores in two therapeutic groups

\begin{tabular}{lcccc} 
& & \multicolumn{2}{c}{ HAM-A score Mean (SD) } & P-value \\
\hline Group G & Number & Before treatment & After treatment & \\
Group D & 32 & $31.53(3.06)$ & $5.84(3.37)$ & $<0.001$ \\
\hline
\end{tabular}

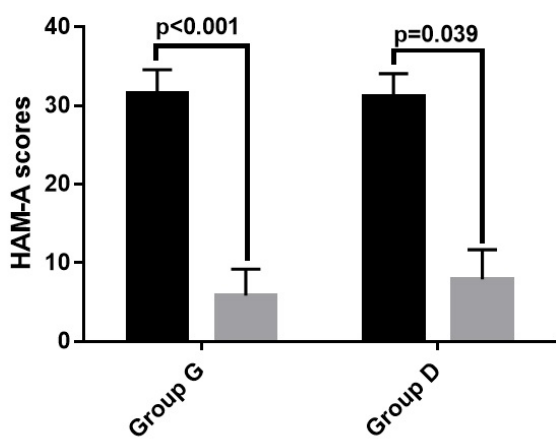

Before treatment

After treatment

Figure 2: Comparison of HAM-A scores in two therapeutic groups.

\section{DISCUSSION}

In this randomized clinical trial, the effects of psychodynamic psychotherapy plus pharmacotherapy versus pharmacotherapy alone, on GAD, PD and mixed anxiety-depressive disorders, were compared. The mean of the pre-treatment HAM-A scores in our study was higher than that in other treatment studies, which ranged from 21.8 to $26.8^{26-28}$. This means that the patients in our study had a more severe pretreatment anxiety state compared to other previous studies.

Both psychodynamic treatment methods could significantly improve the measures of anxiety. After six months of treatment, patients who underwent psychodynamic therapy + pharmacotherapy showed a significantly greater improvement. Blay et al. ${ }^{29} \mathrm{com}-$ pared the effects of a brief group dynamic psychotherapy (BGDP) with routine clinical treatments on patients with minor mental disorders. The two groups were compared based on a general health questionnaire (GHQ) immediately after one month of treatment and after two-year follow-up. Improvement of measures was found in $21.4 \%$ of BGDP patients, which was significantly higher than controls. The authors also demonstrated the positive effects of dynamic group psychotherapy.

Although group therapy most often is considered as a time-saving therapy, this was not the reason we chose it. Indeed, group therapy was chosen based on its high efficacy in treating anxiety patients ${ }^{30}$. Our studyalong with that by Blay et al. ${ }^{29}$ - suggests that analytic group therapy improves the clinical outcomes of patients with minor mental disorders even in shortterm (6 months). In order to improve the clinical outcomes, this treatment can be added to routine treatments (pharmacotherapy).

Other authors have also shown the positive influences of CBT and psychodynamic psychotherapy on mental disorders. Long-term psychodynamic psychotherapy has been shown to be effective by changes in defense styles in depression, anxiety, and personality disorders ${ }^{31}$. Danen et al. ${ }^{31}$ randomly divided $57 \mathrm{pa}$ tients with PD into two groups of CBT and pharmacotherapy + paroxetine; they showed that both treatments improved the short-term outcomes in 4and 12-week follow-ups with no significant differences. Leichsenring et al. ${ }^{28}$ showed that both psychodynamic psychotherapy and CBT were associated with significant improvement in anxiety and depression measures. Furthermore, no significant differences in the two treatments were found for the HAMA score and two other anxiety measures (the Beck Anxiety Inventory and the Hospital Anxiety and Depression Scale). The authors, in fact, showed that CBT was superior for trait anxiety measures (StateTrait Anxiety Inventory), worrying (Penn State Worry Questionnaire), and depression (BDI). According to 
HAM-A as a measure of anxiety, our results confirm those findings by Leichsenring et al. which showed the positive effects of psychodynamic psychotherapy. However, we did not assess patients by other measures except HAM-A.

Although a large number of controlled clinical trials of CBT for anxiety disorders are available, there are only a few for short-term psychodynamic psychotherapy. The results of this study, similar to those of the Leichsenring et al. ${ }^{14}$ study, are promising and encourage psychiatrists to utilize this therapeutic method in the treatment of their anxiety disorder patients.

Pharmacotherapy and psychotherapy can be considered different. One focuses on symptom relief and the other causes dynamic changes in relationships. This is of the challenges of comparing these two treatments in our study. With regard to limitations, a predominant limitation of our study herein is the dissatisfaction of some patients during the intervention (we attempted to resolve their dissatisfaction by a deeper explanation of the purpose of the study).

\section{CONCLUSION}

A significant decline in anxiety measures by combining psychodynamic psychotherapy + pharmacotherapy, versus pharmacotherapy alone, was noticed. Our study showed that psychodynamic psychotherapy could improve pharmacotherapy effects and is superior to pharmacotherapy alone. Further studies are warranted to further define the efficacy of the combined psychodynamic psychotherapy.

\section{ABBREVIATIONS \\ CBT: Cognitive Behavioral Therapy \\ GAD: Generalized Anxiety Disorder PDA: Patholog- ical Demand Avoidance \\ SAD: Seasonal affective Disorder}

\section{ACKNOWLEDGMENTS}

We thank all of personnel in Roozbeh general psychiatric clinic and a private clinic in Tehran for their cooperation.

\section{AUTHOR'S CONTRIBUTIONS}

Study concept and design: SS, SR and MM; Analysis and interpretation of data: MM; Acquisition of data: SS, SR and MM; Drafting of the manuscript: SS, SR and MM; Statistical analysis: MM; Obtained funding: MM; Administrative, technical, or material support: MM and SS; Study supervision: MM. All authors read and approved the final manuscript.

\section{FUNDING}

None.

\section{AVAILABILITY OF DATA AND MATERIALS}

Data and materials used and/or analysed during the current study are available from the corresponding author on reasionable request.

\section{ETHICS APPROVAL AND CONSENT TO PARTICIPATE}

This study was conducted in accordance with the amended Declaration of Helsinki. The institutional review board approved the study, and all participants provided written informed consent.

\section{CONSENT FOR PUBLICATION}

Not applicable.

\section{COMPETING INTERESTS}

The authors declare that they have no competing interests.

\section{REFERENCES}

1. Kim HS, Kim EJ. Effects of relaxation therapy on anxiety disorders: a systematic review and meta-analysis. Archives of psychiatric nursing. 2018;32(2):278-284. PMID: 29579524. Available from: https://doi.org/10.1016/j.apnu.2017.11.015.

2. Leichsenring $F$, Leweke F. Social anxiety disorder. New England Journal of Medicine. 2017;376(23):22552264. PMID: 28591542. Available from: https: //doi.org/10.1056/NEJMcp1614701.

3. Curtiss J, Andrews L, Davis M, Smits J, Hofmann SG. A metaanalysis of pharmacotherapy for social anxiety disorder: an examination of efficacy, moderators, and mediators. Expert opinion on pharmacotherapy. 2017;18(3):243-251. PMID: 28110555. Available from: https://doi.org/10.1080/14656566. 2017.1285907.

4. Kessler RC, Petukhova M, Sampson NA, Zaslavsky AM, Wittchen $\mathrm{H}-\mathrm{U}$. Twelve-month and lifetime prevalence and lifetime morbid risk of anxiety and mood disorders in the United States. Int J Methods Psychiatr Res. 2012;21(3):169-184. PMID: 22865617. Available from: https://doi.org/10.1002/mpr.1359.

5. Wittchen HU, Jacobi F, Rehm J, Gustavsson A, Svensson M, Jonsson $B$, et al. The size and burden of mental disorders and other disorders of the brain in Europe 2010. European neuropsychopharmacology : the journal of the European College of Neuropsychopharmacology. 2011;21(9):655-679. PMID: 21896369. Available from: https://doi.org/10.1016/j. euroneuro.2011.07.018.

6. Chisholm D, Sweeny K, Sheehan P, Rasmussen B, Smit F, Cuijpers $P$, et al. Scaling-up treatment of depression and anxiety: a global return on investment analysis. The lancet Psychiatry. 2016;3(5):415-424. Available from: https://doi.org/10. 1016/S2215-0366(16)30024-4.

7. Jacobi F, Hofler M, Strehle J, Mack S, Gerschler A, Scholl L, et al. [Mental disorders in the general population: Study on the health of adults in Germany and the additional module mental health (DEGS1-MH)]. Der Nervenarzt. 2014;85:77-87. PMID: 24441882. Available from: https://doi.org/10.1007/s00115013-3961-y. 
8. Kessler RC, McGonagle KA, Zhao S, Nelson CB, Hughes M, Eshleman $S$, et al. Lifetime and 12-month prevalence of DSMIII-R psychiatric disorders in the United States. Results from the National Comorbidity Survey. Archives of general psychiatry. 1994;51(1):8-19. PMID: 8279933. Available from: https: //doi.org/10.1001/archpsyc.1994.03950010008002.

9. Kessler RC, Demler O, Frank RG, Olfson M, Pincus HA, Walters $\mathrm{EE}$, et al. Prevalence and treatment of mental disorders, 1990 to 2003. The New England journal of medicine. 2005;352(24):2515-2523. PMID: 15958807. Available from: https://doi.org/10.1056/NEJMsa043266.

10. Bandelow B, Michaelis S. Epidemiology of anxiety disorders in the 21st century. Dialogues Clin Neurosci. 2015;17(3):327335. PMID: 26487813. Available from: https://doi.org/10. 31887/DCNS.2015.17.3/bbandelow.

11. Bandelow B, Michaelis S, Wedekind D. Treatment of anxiety disorders. Dialogues Clin Neurosci. 2017;19(2):93-107. PMID: 28867934. Available from: https://doi.org/10.31887/DCNS 2017.19.2/bbandelow.

12. Benjamin J, Ben-Zion IZ, Karbofsky E, Dannon P. Double-blind placebo-controlled pilot study of paroxetine for specific phobia. Psychopharmacology. 2000;149(2):194-196. PMID: 10805616. Available from: https://doi.org/10.1007/s002130000372.

13. Creswell C, Waite P, Cooper PJ. Assessment and management of anxiety disorders in children and adolescents. Archives of disease in childhood. 2014;99(7):674-678. PMID: 24636957. Available from: https://doi.org/10.1136/archdischild-2013303768.

14. James AC, James G, Cowdrey FA, Soler A, Choke A Cognitive behavioural therapy for anxiety disorders in children and adolescents. The Cochrane database of systematic reviews. 2013;(6):Cd004690. https://doi.org/10.1002/14651858.CD004690.pub3.

15. Otte C. Cognitive behavioral therapy in anxiety disorders: current state of the evidence. Dialogues Clin Neurosci. 2011;13(4):413-421. PMID: 22275847. Available from: https: //doi.org/10.31887/DCNS.2011.13.4/cotte.

16. Tolin DF. Is cognitive-behavioral therapy more effective than other therapies? A meta-analytic review. Clinical psychology review. 2010;30(6):710-720. PMID: 20547435. Available from: https://doi.org/10.1016/j.cpr.2010.05.003.

17. Wolgensinger L. Cognitive behavioral group therapy for anxiety: recent developments. Dialogues Clin Neurosci. 2015;17(3):347-351. PMID: 26487815. Available from: https: //doi.org/10.31887/DCNS.2015.17.3/lwolgensinger.

18. Bandelow B, Lichte T, Rudolf S, Wiltink J, Beutel ME. The diagnosis of and treatment recommendations for anxiety disorders. Deutsches Arzteblatt international. 2014;111(2728):473-480. PMID: 25138725. Available from: https://doi.org/ 10.3238/arztebl.2014.0473.

19. Barlow DH, Gorman JM, Shear MK, Woods SW. Cognitivebehavioral therapy, imipramine, or their combination for panic disorder: A randomized controlled trial. Jama. 2000;283(19):2529-2536. PMID: 10815116. Available from https://doi.org/10.1001/jama.283.19.2529.

20. Knijnik DZ, Kapczinski F, Chachamovich E, Margis R, Eizirik CL. [Psychodynamic group treatment for generalized social phobia]. Revista brasileira de psiquiatria (Sao Paulo, Brazil : 1999. 2004;26(2):77-81. PMID: 15517057. Available from: https:
//doi.org/10.1590/S1516-44462004000200003.

21. Schottenbauer MA, Glass CR, Arnkoff DB, Tendick V, Gray $\mathrm{SH}$. Nonresponse and dropout rates in outcome studies on PTSD: review and methodological considerations. Psychiatry. 2008;71(2):134-168. PMID: 18573035. Available from: https://doi.org/10.1521/psyc.2008.71.2.134.

22. Bandelow B, Reitt M, Rover C, Michaelis S, Gorlich $Y$ Wedekind D. Efficacy of treatments for anxiety disorders: a meta-analysis. International clinical psychopharmacology. 2015;30(4):183-192. PMID: 25932596. Available from: https: //doi.org/10.1097/YIC.0000000000000078.

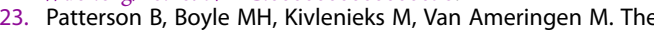
use of waitlists as control conditions in anxiety disorders research. Journal of psychiatric research. 2016;83:112-120. PMID: 27585425. Available from: https://doi.org/10.1016/j. jpsychires.2016.08.015.

24. Schermer V, Pines $M$. Attacks on the reflective space. Ring of Fire. London and New York: Routledge. 2004;p. 97-100.

25. American Psychiatric Association. Diagnostic and statistical manual of mental disorders (DSM-5 $5^{\circ}$ ). American Psychiatric Pub. 2013;Available from: https://doi.org/10.1176/appi.books. 9780890425596

26. Borkovec TD, Newman MG, Pincus AL, Lytle R. A component analysis of cognitive-behavioral therapy for generalized anxiety disorder and the role of interpersonal problems. Journal of consulting and clinical psychology. 2002;70(2):288298. PMID: 11952187. Available from: https://doi.org/10.1037/ 0022-006X.70.2.288

27. Linden M, Zubraegel D, Baer T, Franke U, Schlattmann P. Efficacy of cognitive behaviour therapy in generalized anxiety disorders. Results of a controlled clinical trial (Berlin CBT-GAD Study). Psychotherapy and psychosomatics. 2005;74(1):3642. PMID: 15627855. Available from: https://doi.org/10.1159/ 000082025 .

28. Leichsenring $F$, Salzer $S$, Jaeger $U$, Kachele $H$, Kreische $R$, Leweke $F$, et al. Short-term psychodynamic psychotherapy and cognitive-behavioral therapy in generalized anxiety disorder: a randomized, controlled trial. The American journal of psychiatry. 2009;166(8):875-881. PMID: 19570931. Available from: https://doi.org/10.1176/appi.ajp.2009.09030441.

29. Blay SL, Vel Fucks JS, Barruzi M, Di Pietro MC, Gastal FL, Neto $A M$, et al. Effectiveness of time-limited psychotherapy for minor psychiatric disorders: randomised controlled trial evaluating immediate $v$. long-term effects. The British journal of psychiatry : the journal of mental science. 2002;180:416-422. PMID: 11983638. Available from: https://doi.org/10.1192/bjp. 180.5.416.

30. Slavin-Mulford J., Hilsenroth M.J. (2012) Evidence-Based Psychodynamic Treatments for Anxiety Disorders: A Review. In Levy R., Ablon J., Kächele H. (eds) Psychodynamic Psychotherapy Research. Current Clinical Psychiatry. Humana Press, Totowa, NJ. 2012;p. 117-137. Available from: https://doi.org/10. 1007/978-1-60761-792-1_7.

31. Dannon PN, Gon-Usishkin M, Gelbert A, Lowengrub K, Grunhaus L. Cognitive behavioral group therapy in panic disorder patients: the efficacy of CBGT versus drug treatment. Annals of clinical psychiatry : official journal of the American Academy of Clinical Psychiatrists. 2004;16(1):4146. PMID: 15147112. Available from: https://doi.org/10.1080/ 10401230490281609 